\title{
The SBAR Communication Framework: For When You Need Action
}

David Stonehouse is a Lecturer in Children and Young People's Nursing with the School of Health and Society at the University of Salford, Manchester.

\begin{abstract}
.
This article examines the communication framework known as SBAR (situation, background, assessment, recommendation). High quality communication between members of the multi-disciplinary team is vital within health and social care. Support workers have a clear role and responsibility in facilitating effective communication. Therefore relevant sections of The Code of Conduct for Healthcare Support Workers and Adult Social Care Workers in England (Skills for Care and Skills for Health, 2013) will be highlighted. The article will then discuss exactly what the SBAR framework is and examine the four key parts which assist in the concise and focused transfer of information in an assertive and effective way, while empowering the support worker and developing their critical thinking skills.
\end{abstract}

Key Words: Assessment, Background, Communication, Recommendation, SBAR, Situation, Support Workers.

\section{$\underline{\text { Introduction }}$}

Support workers, whether working in the community or hospital setting, are often the first professional to identify when a problem arises. This problem could be a deterioration in a patient's condition or the development of a new issue requiring intervention. If in hospital you may need to contact the doctor, nurse, or physiotherapist. If working within the community it may be the clients G.P; the district nurse, community psychiatric nurse, or social worker. Communicating this often urgent need to another health or social care professional can be problematic and stressful. Questions such as what information will they need? Will I forget to include something important? How do I communicate the urgency of the situation to someone who is already potentially very busy with other prioritises? As Marquis and Huston (2017) state it is the responsibility of the sender (the support worker) to make sure that the message has been understood by the receiver and will be acted upon. One way that this can be done is to use a communication framework which other professional groups are already familiar with and are using.

Code Words. 
The importance of the support worker communicating and collaborating effectively is reinforced by The Code of Conduct for Healthcare Support Workers and Adult Social Care Workers in England (Skills for Care and Skills for Health, 2013). Two key sections stand out, section three, working in collaboration and section four, communication. Section 3.1 starts this section on collaboration with the important assertion that support workers must value and understand the vital part their contribution plays within their team. This statement of fact should empower support workers and encourage them to voice their concerns and knowledge of their patients/clients condition with their colleagues. Section 3.3 states the support worker must "work openly and co-operatively with colleagues including those from other disciplines and agencies, and treat them with respect." This is clearly a vital part of the caring role, to work with and refer to the wider multidisciplinary team of health and social care professionals as and when required. Section 3.6 completes this section stating support workers must "actively encourage the delivery of high quality healthcare, care and support." One important way in which this is achieved is through successful communication between all members of the patient's team. This is reinforced in section 4.2 which states support workers must "communicate effectively and consult with your colleagues as appropriate." Through using a communication framework such as SBAR will assist the support worker to achieve these clear standards.

\section{What is the SBAR Communication Framework?}

Originally developed by the United States Navy and now adopted by the National Health Service (NHS Institute for Innovation and Improvement, 2010, NHS Improvement, 2018) is the SBAR framework. SBAR consists of four key building blocks and stands for situation, background, assessment and recommendation. By following these four stages the support worker will be able to share "concise and focused information" (NHS Improvement, 2018) with the individuals who need it. The Royal College of Physicians (2018:144) states that the tool empowers individuals to communicate effectively and assertively, while "encouraging critical thinking." Importantly "SBAR prevents the hit and miss process of "hinting and hoping"' that the information has been understood and contributes to increased patient safety and effective escalation of the clinical problem (NHS Institute for Innovation and Improvement, 2010:7).

\section{Situation}

This is the first part of the SBAR communication framework. However, before you start to describe the situation you need right at the beginning of the conversation to clearly state who you are and where you are calling from. Cudjoe (2016) advocates for adding in another section to the framework, 'l' for Identity making the acronym ISBAR. Emphasising the importance of this step. However most authors (Coley, 2015, NHS Improvement, 2018, NHS Institute for Innovation and Improvement, 2010) agree that it is sufficient to have identity as part of situation. Whether identity 
has its own section at the beginning or is incorporated into the situation section, it is important it is included so that the receiver of the information knows who they are talking to and where the patient is, especially if you require them to attend.

Moving on from your identity and location you now need to state the issue that you want to discuss. What is your concern about the patient or situation? Why are you calling?

\section{Background}

You then need to state the background to the patient. If an inpatient state the reason for the admission, when admitted, diagnosis and current treatment. Inform the person of any relevant medical history. If in the community it might be the ongoing medical condition of the patient and care they receive. You will need the relevant documentation to hand, patient's notes, observation charts, in order to accurately relay this information.

\section{$\underline{\text { Assessment }}$}

You then need to state your assessment of the patient. What are their current vital signs, what are your concerns? Have they deteriorated since the last time they were assessed by a doctor or nurse? If you know what the problem is then say so. Equally if you do not know the cause, but you know there is something wrong and are concerned then state this.

\section{$\underline{\text { Recommendation }}$}

The final part of the framework is for you to state clearly what it is you need the person you are communicating with to do. As stated by NHS Improvement (2018) "explain what you need - be specific about request and time frame, make suggestions, clarify expectations." If you require the person to come immediately to review the patient then say so. The receiver needs to be able to prioritise their workload and who they see next and who can wait half an hour.

The importance of the receiver reading back a summary of the information to the support worker is stressed by the NHS Institute for Innovation and Improvement (2010). This will ensure that the information has been transferred accurately and clearly and that you have been understood. Any discrepancies can then be rectified.

\section{Conclusion.}

So to conclude, this article has highlighted the usefulness and importance of using the SBAR communication framework to facilitate good communication between individuals and across professional groups. Support workers are often working closely with patients and are often the first professional to identify a deterioration in condition or an issue arising. Through the use of SBAR support workers will be 
empowered to communicate effectively and assertively for the good of their patients and clients, accessing timely and appropriate help when required.

\section{Key Points:}

1. Support workers are often the first professional to identify when a problem arises.

2. Support workers are responsible to make sure that information communicated is understood by the receiver.

3. The use of SBAR increases patient safety and the effective escalation of clinical and social concerns.

4. SBAR will help to empower support workers to communicate more effectively for the good of their patients.

5. Stating exactly what you want to happen at the end of the conversation is a key part to the SBAR tool.

\section{$\underline{\text { Reflective Questions For Your Continuing Professional Development }}$}

- What support would you require for you and your team to implement using the SBAR framework to improve communication?

- Reflect upon a good and bad conversation you have had with another heath or social care professional and identify what made it so?

- Practice role playing a conversation with a colleague using the SBAR framework.

\section{$\underline{\text { References: }}$}

Coley M (2015) Communication and the 6Cs Using the SBAR Tool. British Journal of Healthcare Assistants. 9(4): 202-203

Cudjoe K G (2016) Add Identity to SBAR. Nursing Made Incredibly Easy. 14(1): 6-7

Marquis B L \& Huston C J (2017) Leadership Roles and Management Functions in Nursing: Theory and Application. $9^{\text {th }}$ edn. Philadelphia: Wolters Kluwer

NHS Improvement (2018) SBAR Communication Tool - Situation, Background, assessment, Recommendation. https://improvement.nhs.uk/documents/2162/sbarcommunication-tool.pdf (accessed 7 June 2018)

NHS Institute for Innovation and Improvement (2010) Safer Care: SBAR Situation, background, Assessment, Recommendation: Implementation and Training Guide. https://www.england.nhs.uk/improvement-hub/wpcontent/uploads/sites/44/2017/11/SBAR-Implementation-and-Training-Guide.pdf (accessed 7 June 2018) 
Royal College of Physicians (2018) Team Communication. British Journal of Healthcare Assistants. 12(3): 142-147

Skills for Care and Skills for Health (2013) Code of Conduct for Healthcare Support Workers and Adult Social Care Workers in England.

http://www.skillsforhealth.org.uk/images/services/code-of-

conduct/Code\%20of\%20Conduct\%20Healthcare\%20Support.pdf (accessed 7 June 2018) 